\title{
Absence epilepsy and the CHD2 gene: an adolescent male with moderate intellectual disability, short-lasting psychoses, and an interstitial deletion in I5q26. I-q26.2
}

\author{
This article was published in the following Dove Press journal: \\ Neuropsychiatric Disease and Treatment \\ 10 May 2016 \\ Number of times this article has been viewed
}

\author{
Willem MA Verhoeven ${ }^{1,2}$ \\ Jos IM Egger ${ }^{1,3,4}$ \\ Alida C Knegt ${ }^{5}$ \\ José Zuydam ${ }^{6}$ \\ Tjitske Kleefstra ${ }^{7}$ \\ 'Centre of Excellence for \\ Neuropsychiatry, Vincent van Gogh \\ Institute for Psychiatry, Venray, \\ ${ }^{2}$ Department of Psychiatry, Erasmus \\ University Medical Center, Rotterdam, \\ ${ }^{3}$ Donders Institute for Brain, \\ Cognition and Behaviour, ${ }^{4}$ Behavioural \\ Science Institute, Radboud University, \\ Nijmegen, ${ }^{5}$ Department of Clinical \\ Genetics, University of Amsterdam \\ Medical Center, Amsterdam, \\ ${ }^{6}$ Reigersdaal Institute for Intellectual \\ Disabilities, Heerhugowaard, \\ ${ }^{7}$ Department of Genetics, Radboud \\ University Medical Centre, Nijmegen, \\ the Netherlands
}

\begin{abstract}
Deletions of the $15 \mathrm{q} 26$ region encompassing the chromodomain helicase DNA binding domain 2 (CHD2) gene have been associated with intellectual disability, behavioral problems, and several types of epilepsy. Including the cases mentioned in ECARUCA (European cytogeneticists association register of unbalanced chromosome aberrations) and DECIPHER (database of genomic variation and phenotype in humans using ensembl resources), so far, a total of 13 intellectually disabled patients with a genetically proven deletion of the $C H D 2$ gene are described, of whom eleven had a history of severe forms of epilepsy starting from a young age. In this article, a moderately intellectually disabled 15 -year-old male with a 15q26.1-q26.2 interstitial deletion is reported, who was referred for analysis of two recent short-lasting psychotic episodes that were nonresponsive to antipsychotic treatment and recurrent disinhibited behaviors since early infancy. Careful interdisciplinary assessment revealed that the psychotic phenomena originated from a previously unrecognized absence epilepsy. Treatment with valproic acid was started which resulted in full remission of psychotic symptoms, and consequently, substantial improvement of behavior. It was concluded that in case of (rare) developmental disorders with genetically proven etiology, a detailed inventory of anamnestic data and description of symptomatology over time may elucidate epilepsy-related psychopathology for which a specific treatment regimen is needed.
\end{abstract}

Keywords: 15 q26.1 interstitial deletion, CHD2 gene, intellectual disability, epilepsy, psychotic disorder, neuropsychology

\section{Introduction}

Microarray analysis has been shown to be of crucial importance for the understanding of the genetic etiology of intellectual disability (ID). With this technique, numerous (de novo) copy number variations have been discovered leading to several circumscribed microdeletion syndromes. ${ }^{1,2}$ Especially in patients in whom neuropsychiatric disorders or congenital anomalies are present, in addition to ID, extensive genetic analysis is warranted.

Partial deletions of the long arm of chromosome 15, particularly in the $15 \mathrm{q} 26$ region, have been typically associated with somatic anomalies, especially congenital diaphragmatic hernia. ${ }^{3}$ In addition, ID, epilepsy, and behavioral problems are frequently mentioned. ${ }^{4-6}$ With respect to the $15 \mathrm{q} 26.1$ subregion, the chromodomain helicase DNA binding domain 2 (CHD2) gene (OMIM: 602119), originally characterized by Woodage et $\mathrm{al},{ }^{7}$ has been repeatedly reported to play a pivotal role in cerebrocortical development. ${ }^{8}$ Both microdeletions encompassing this gene and de novo loss of
Correspondence: Willem MA Verhoeven Centre of Excellence for Neuropsychiatry, Vincent van Gogh Institute for Psychiatry, Stationsweg 46, 5803 AC Venray, the Netherlands

Tel +3I 0478527339

Email wmaverhoeven@planet.nl 
function mutations lead to a syndrome characterized by ID and epileptic encephalopathy with generalized seizures. ${ }^{9,10}$

So far, a total of nine patients with ID (seven females and two males) has been reported with a genetically proven deletion of the CHD2 gene. Of these patients, eight had a history of severe forms of epilepsy starting from the young age. ${ }^{4-6,11,12}$

Here, a 15-year-old male with a 15q26.1-q26.2 interstitial deletion is described, who was referred to the specialized outpatient department for psychopathology and genetics because of short-lasting psychotic episodes and problematic management of disinhibited behaviors for which over many years symptomatic treatment with antipsychotics (ie, haloperidol) was ineffective.

\section{Clinical description}

The patient is a 15-year-old male of Chinese origin, who was adopted at the age of 18 months in a malnourished condition from an orphanage by his Dutch foster parents. Shortly after birth, in the People's Republic of China, he underwent the first surgical correction for bilateral cheilognathopalatoschisis followed by several reconstructive surgeries in the Netherlands up to the age of 5 years. Upon arrival, he was referred to a pediatrician of a university hospital for evaluation of developmental delay as well as bizarre autistic and disinhibited behaviors. At examination, apart from moderate auditory impairment secondary to recurrent upper airway infections, mild motor delay was noticed for which physical therapy was applied. Full laboratory investigation according to the Dutch adoption protocol, including screening for metabolic disorders, disclosed no abnormalities. Electroencephalogram (EEG) registration revealed focal frontocentral abnormalities that were difficult to interpret because of muscular artifacts.
At the age of 2 years, a symptomatic treatment with a low dose of haloperidol was started because of persisting challenging behavior. Subsequently, he was extensively examined by a child neurologist at the age of 5 years. Weight, length, and head circumference were $17.4 \mathrm{~kg}$ ( -1 standard deviation [SD]), $110 \mathrm{~cm}$ (0 SD), and $46 \mathrm{~cm}$ (-2 SD), respectively. No abnormalities were found apart from motor overactivity. His attention was undisturbed, whereas communication was adequate with the use of a hearing aid. Since his parents frequently noticed brief moments with a blank staring and unresponsiveness to his surroundings, EEG recording was performed, which showed similar frontal irregularities without, however, specific epileptic configurations. A diagnosis of aspecific psychomotor retardation was made. Six months later, due to aggressive, self-injurious, and autistic behaviors, reevaluation by a pediatrician was performed, who advised a more congruent and structured behavioral approach.

During subsequent years, various interventions with antipsychotics for behavioral control were implemented, which, however, frequently induced unwanted side effects such as dyskinesias, akathisia, and facial edema. In this period, intelligence testing was performed twice with an interval of 3 years showing a total intelligence quotient (IQ) of 55 and a developmental age of $\sim 3.6$ years (calendar age: 8 years). At the age of 12 years, microarray analysis (Agilent 180K oligoarray, amadid 023363 [Agilent Technologies, Santa Clara, CA, USA]) demonstrated an $1.8 \mathrm{Mb}$ interstitial deletion in 15q26.1-q26.2, encompassing the $C D H 2$ and $R G M A$ genes that were considered to be etiologically involved (karyotype: arr[hg19]15q26.1q26.2(93,408,53295,188,862)x1; Figure 1). Magnetic resonance imaging scan of the brain showed no abnormalities.

In the next 18 months, two short-lasting episodes occurred characterized by marked global regression, anxieties, hallucinatory experiences (visual and auditory), as well as

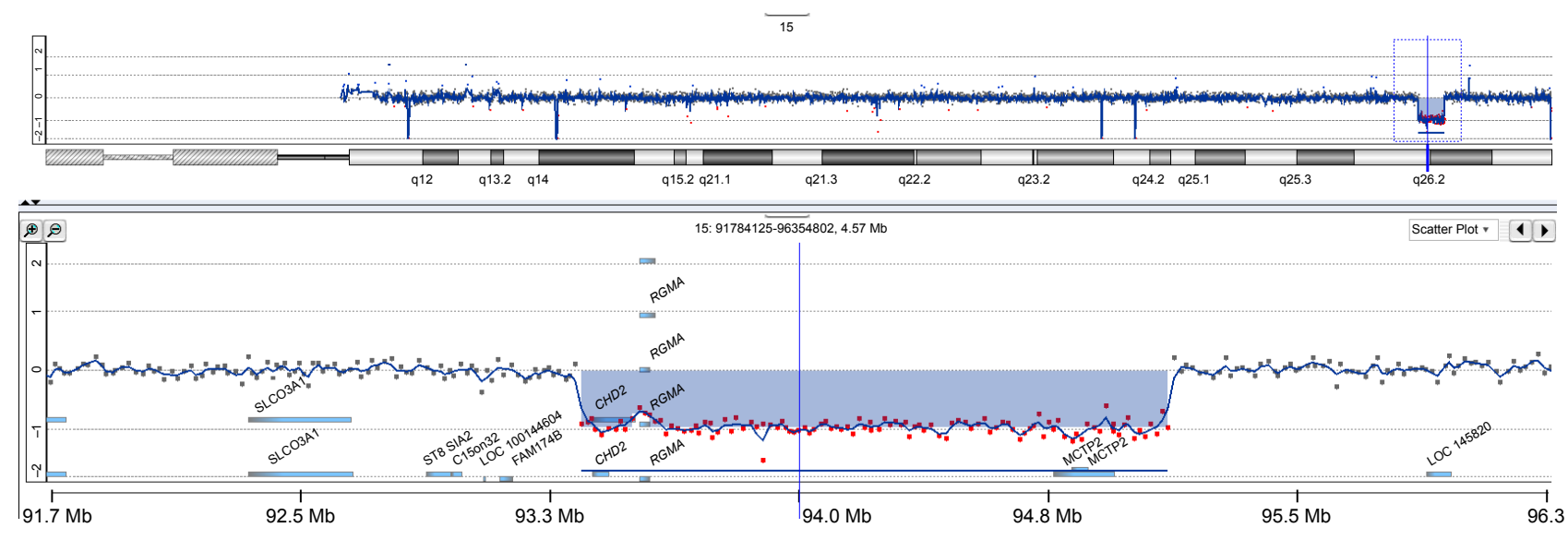

Figure I Copy number profile of chromosome 15 of the patient obtained by oligoarray-based comparative genomic hybridization (I80K platform). Note: The chromosome 15 copy number imbalance in 15q26.1-q26.2 is shown in detail. 
disinhibited and aggressive behaviors. Treatment with haloperidol and promethazine in a twice-daily dose of 1.5 and $25 \mathrm{mg}$, respectively, was prescribed with, however, insufficient efficacy. As a consequence, the patient was referred to the specialized outpatient facility for psychopathology and genetics for integrative assessment of behavior and psychopathology in the context of the genetic condition. Written informed consent has been obtained from the mother of the patient. This study has been approved by the Vincent van Gogh Institutional Review Board.

\section{Results}

At examination, a young male adolescent was seen with a status after multiple reconstructive surgical corrections for bilateral cheilognathopalatoschisis. No dysmorphias were noticed. His behavioral repertoire comprised compulsive elements, hyperactivity, and impulsivity. No major psychiatric symptoms could be identified. Detailed heteroanamnestic evaluation revealed that, since the age of 13 years, two short-lasting psychotic episodes had occurred dominated by anxieties, dysphoric mood swings, threatening and disinhibited behaviors, physical aggression, and both visual and auditory hallucinations, accompanied by diminished consciousness as well as restricted interpersonal contact.

Routine hematological and biochemical laboratory tests were all normal. Pharmacogenetic analysis demonstrated no abnormalities for CYP2C9 and CYP2C19. For CYP2D6, however, $\mathrm{a} * 10 / * 10$ genotype was found that is in accordance with a significantly impaired biotransformation capacity.

Extensive neuropsychological assessment (Vineland screener, ${ }^{13}$ VISK $^{14}$ ) showed a developmental age of 2 years with a discrepant profile (social: 0.8 years; motor and communication: $>2.6$ years). Formal intelligence testing could not be fully performed due to major impairments of attention and inhibitory functioning as well as repetitive behaviors. The latter was objectivated by proxy ratings of attention and executive functioning (BRIEF, ${ }^{15}$ BADS-DEX ${ }^{16}$ ). Assessment of psychopathology by means of the psychopathology instrument for mentally retarded adults pointed specifically at chaotic, anxious, and generally inadaptive behaviors (total score: 32 ; maximum: 56$).{ }^{17}$

Based on the aforementioned information, a preliminary diagnosis of epilepsy-related recurrent brief psychosis was made and it was advised to perform EEG recording. The latter revealed that some epileptic paroxysms left frontotemporal and sporadic polyspike-wave complexes. For this reason, the antiepileptic compound valproic acid was prescribed, whereas symptomatic treatment for behavioral control with a low dose of haloperidol (1.6 mg daily [gtt]; plasma concentration: $1 \mu \mathrm{g} / \mathrm{L}$ ) was continued. This antiepileptic intervention (600 mg valproic acid; plasma concentration: $85 \mathrm{mg} / \mathrm{L}$ ) resulted in a full remission of psychotic symptoms and a gradual normalization of behavior to the premorbid level that, apart from incidentally occurring odd beliefs, was paralleled by stabilization of mood and marked improvement of social adaptation.

\section{Discussion}

In the moderately intellectually disabled patient presented here, psychotic phenomena appeared to be the result of a previously unrecognized absence epilepsy. Treatment with valproic acid induced a substantial improvement of his behavior while keeping free from further psychotic episodes. As stressed by several authors, epilepsy-related psychoses, both post- and interictal, are still a clinical challenge to recognize and treat appropriately. ${ }^{18,19}$

The 15q26.1 microdeletion, encompassing among others the CHD2 gene, is in general associated with febrile seizures starting at early age followed by various epileptic features, myoclonic as well as tonic-clonic and absence seizures, and not typically clear dysmorphisms. ${ }^{9,10}$ In the current patient, absence epilepsy was only present. Out of a total of nine published cases, this type of epilepsy is mentioned in two, whereas in one, no epilepsy was present (Table 1). As can be inferred, in addition to the published cases, four

Table I Reported patients with a 15q26 microdeletion encompassing the CHD2 gene, intellectual disability, and challenging behaviors $^{\mathrm{a}}$

\begin{tabular}{|c|c|c|c|c|c|c|}
\hline Study & $\begin{array}{l}\text { Patient } \\
\text { number }\end{array}$ & $\begin{array}{l}\text { Sex/age } \\
\text { (years) }\end{array}$ & $\begin{array}{l}\text { Deletion } \\
\text { size }\end{array}$ & Dysmorphisms & Epilepsy & Remarks \\
\hline Veredice et $\mathrm{al}^{4}$ & I & $F / 2.6$ & $\sim 5 \mathrm{Mb}$ & + & $t^{\mathrm{b}}$ & Congenital hypothyroidism \\
\hline Dhamija et $\mathrm{al}^{5}$ & 1 & $F / 9$ & $\sim 731 \mathrm{~kb}$ & + & $t^{\mathrm{b}}$ & \\
\hline \multirow[t]{2}{*}{ Capelli et $\mathrm{al}^{6}$} & I & $\mathrm{F} / 6$ & $\sim 500 \mathrm{~kb}$ & + & + & Gate ataxia \\
\hline & & & & & & Also deletion of RGMA \\
\hline \multirow[t]{2}{*}{ Courage et al" } & I & $M / 25$ & $\sim 415 \mathrm{~kb}$ & + & + & Also deletion of RGMA \\
\hline & 2 & $M / 21$ & $\sim 106 \mathrm{~kb}$ & + & + & Also deletion of RGMA \\
\hline \multirow[t]{2}{*}{ Chénier et al ${ }^{12}$} & I & $\mathrm{F} / \mathrm{II}$ & $\sim 191 \mathrm{~kb}$ & + & + & Auditory neuropathy \\
\hline & 2 & $\mathrm{~F} / 9$ & $\sim 210 \mathrm{~kb}$ & + & + & \\
\hline
\end{tabular}

(Continued) 
Table I (Continued)

\begin{tabular}{|c|c|c|c|c|c|c|}
\hline Study & $\begin{array}{l}\text { Patient } \\
\text { number }\end{array}$ & $\begin{array}{l}\text { Sex/age } \\
\text { (years) }\end{array}$ & $\begin{array}{l}\text { Deletion } \\
\text { size }\end{array}$ & Dysmorphisms & Epilepsy & Remarks \\
\hline & 3 & $\mathrm{~F} / 6$ & $\sim 78 \mathrm{~kb}$ & + & - & \\
\hline & 4 & $F / 16$ & $\sim 237 \mathrm{~kb}$ & - & + & Also deletion of RGMA \\
\hline ECARUCA & 4,878 & $M / 22$ & $\sim 106 \mathrm{~kb}$ & + & + & Also deletion of $R G M A$ \\
\hline database & 5,121 & $\mathrm{~F} / 27.5$ & $\sim 4.2 \mathrm{Mb}$ & + & + & $\begin{array}{l}\text { Congenital cardiovascular anomaly } \\
\text { Also deletion of RGMA }\end{array}$ \\
\hline DECIPHER & 270,487 & $\mathrm{~F} / 3$ & $\sim 4.05 \mathrm{Mb}$ & ns & + & Also deletion of RGMA \\
\hline database & 304,608 & $\mathrm{~F} / \mathrm{I} 5$ & $\sim 240 \mathrm{~kb}$ & ns & - & Also deletion of RGMA \\
\hline Present patient & I & $M / I 5$ & $\sim 1.8 \mathrm{Mb}$ & - & + & $\begin{array}{l}\text { Bilateral cheilognathopalatoschisis } \\
\text { Also deletion of RGMA }\end{array}$ \\
\hline
\end{tabular}

Notes: ${ }^{\mathrm{B}}$ Both Pinto et $\mathrm{a}^{21}$ and Hamdan et a ${ }^{22}$ report patients with a deletion of the CHD2 gene, who were both identified from large-scale studies on CNVs in patients with intellectual disability and/or autism spectrum disorder. No further information is available. 'Epilepsy reported drug resistance. "+", present; “-”, absent.

Abbreviations: F, female; M, male; ns, not significant; CNVs, copy number variations; ECARUCA, European cytogeneticists association register of unbalanced chromosome aberrations; DECIPHER, database of genomic variation and phenotype in humans using ensembl resources.

patients are registered in international databases of whom one (DECIPHER 304608) was not diagnosed with epilepsy. Finally, two patients were detected in large copy-number variation studies, but no clinical information about their phenotype or presence of epilepsy is provided.

In eight patients, the $15 \mathrm{q} 26.1$ deletion also encompassed the RGMA gene (OMIM: 607362) that is assumed to be involved in immune functionality but not regarded to be of clinical significance for ID or epilepsy. ${ }^{20}$

\section{Conclusion}

This case demonstrates the vital importance of detailed anamnesis and careful description of the symptom-cognitionbehavior complex over time, both to ensure early detection of epilepsy-related psychopathology, especially in people with ID, and to avoid diagnostic misinterpretation and inappropriate treatment.

\section{Disclosure}

The authors report no conflicts of interests in this work.

\section{References}

1. Vissers LE, de Ligt J, Gilissen C, et al. A de novo paradigm for mental retardation. Nat Genet. 2010;42:1109-1113.

2. Gilissen C, Hehir-Kwa JY, Tjwan Thung D, et al. Genome sequencing identifies major causes of severe intellectual disability. Nature. 2014; 511:344-347.

3. Klaassens M, Galjaard RJ, Scott DA, et al. Prenatal detection and outcome of congenital diaphragmatic hernia $(\mathrm{CDH})$ associated with deletion of chromosome 15q26: two patients and review of the literature. Am J Med Genet. 2007;143A:2201-2212.

4. Veredice C, Bianco F, Contaldo I, et al. Early onset myoclonic epilepsy and 15 q26 microdeletion: observation of the first case. Epilepsia. 2009; 50:1810-1815.

5. Dhamija R, Breningstall G, Wong-Kisiel L, Dolan M, Hirsch B, Wirrell E. Microdeletion of chromosome $15 \mathrm{q} 26.1$ in a child with intractable generalized epilepsy. Pediatr Neurol. 2011;45:60-62.

6. Capelli LP, Krepischi ACV, Gurgel-Giannetti J, et al. Deletion of the $R M G A$ and $C D H 2$ genes in a child with epilepsy and mental deficiency. Eur J Med Genet. 2012;55:132-134.
7. Woodage T, Basrai MA, Baxevanis AD, Hieter P, Collins FS. Characterization of the CDH family of proteins. Proc Natl Acad Sci U S A. 1997; 94:11472-11477.

8. Shen T, Ji F, Yuan Z, Jiao J. CHD2 is required for embryonic neurogenesis in the developing cerebral cortex. Stem Cells. 2015;33:1794-1806.

9. Suls A, Jaehn JA, Kecskés A, et al. De novo loss-of-function mutations in CHD2 cause a fever-sensitive myoclonic epileptic encephalopathy sharing features with Dravet syndrome. Am J Hum Genet. 2013;93:967-975.

10. Carvill GL, Heavin SB, Yendle SC, et al. Targeted resequencing in epileptic encephalopathies identifies de novo mutation in CHD2 and SYNGAP1. Nat Genet. 2013;45:825-830.

11. Courage C, Houge G, Gallati S, Schjelderup J, Rieubland C. 15q26.1 microdeletion encompaasing only CHD2 and RGMA in two adults with moderate intellectual disability, epilepsy and truncal obesity. Eur J Med Genet. 2014;57:520-523.

12. Chénier S, Yoon G, Argiropoulos B, et al. CHD2 haploinsufficienty is associated with developmental delay, intellectual disability, epilepsy and neurobehavioural problems. J Neurodev Disord. 2014;6:9.

13. Scholte E, Van Duijn E, Dijkxhoorn Y. Vineland Screener 0-6 Years: Manual of the Dutch Adaptation. Leiden: PITS; 2008.

14. Hartman C, Luteijn E, Moorlag-Jonker H, de Bildt A, Minderaa R. VISK Test Manual. Amsterdam: Boom; 2015.

15. Gioia G, Isquith P, Guy S, Kenworthy L. Behavior Rating Inventory of Executive Functioning (BRIEF): Professional Manual. Lutz, FL: Psychological Assessment Resources; 2000.

16. Wilson B, Alderman N, Burgess P, Emslie H, Evans J. BADS: Behavioural Assessment of the Dysexecutive Syndrome. London: Pearson; 1997.

17. Matson JL, Kazdin AE, Senatore V. Psychometric properties of the psychopathology instrument for mentally retarded adults. Appl Res Ment Retard. 1994;5:81-89.

18. Maramatsu R, Kubo T, Mori M, et al. RGMa modulates T cell responses and is involved in autoimmune encephalomyelitis. Nat Med. 2011;17: 488-494.

19. Gaitatzis A, Trimble MR, Sander JW. The psychiatric comorbidity of epilepsy. Acta Neurol Scand. 2004;110:207-220.

20. Verhoeven WMA, Egger JIM, Gunning WB, Bevers M, de Pont BJ. Recurrent schizophrenia-like psychosis as first manifestation of epilepsy: a diagnostic challenge in neuropsychiatry. Neuropsychiatr Dis Treat. 2010;6:227-231.

21. Pinto D, Pagnamenta AT, Klei L, et al. Functional impact of global rare copy number variation in autism spectrum disorder. Nature. 2010; 466:368-372.

22. Hamdan FF, Sroer M, Capo-Chichi JM, et al. De novo mutations in moderate or severe intellectual disability. PLoS Genet. 2014;10: e1004772. 


\section{Publish your work in this journal}

Neuropsychiatric Disease and Treatment is an international, peerreviewed journal of clinical therapeutics and pharmacology focusing on concise rapid reporting of clinical or pre-clinical studies on a range of neuropsychiatric and neurological disorders. This journal is indexed on PubMed Central, the 'PsycINFO' database and CAS, and is the official journal of The International Neuropsychiatric Association (INA). The manuscript management system is completely online and includes a very quick and fair peer-review system, which is all easy to use. Visit http://www.dovepress.com/testimonials.php to read real quotes from published authors.

\footnotetext{
Submit your manuscript here: http://www.dovepress.com/neuropsychiatric-disease-and-treatment-journal
} 